\title{
BMJ Open Management of diabetes and associated costs in a complex humanitarian setting in the Democratic Republic of Congo: a retrospective cohort study
}

\author{
Éimhín Mary Ansbro (D) , ${ }^{1,2}$ Michel Biringanine, ${ }^{3}$ Grazia Caleo, ${ }^{1}$ \\ David Prieto-Merino, ${ }^{4}$ Zia Sadique, ${ }^{5}$ Pablo Perel, ${ }^{6}$ Kiran Jobanputra, ${ }^{1}$ \\ Bayard Roberts ${ }^{7}$
}

To cite: Ansbro ÉM, Biringanine $\mathrm{M}$, Caleo $\mathrm{G}$, et al. Management of diabetes and associated costs in a complex humanitarian setting in the Democratic Republic of Congo: a retrospective cohort study. BMJ Open 2019;9:e030176. doi:10.1136/ bmjopen-2019-030176

- Prepublication history and additional material for this paper are available online. To view these files, please visit the journal online (http://dx.doi. org/10.1136/bmjopen-2019030176).

Received 01 March 2019 Revised 22 October 2019 Accepted 23 October 2019

Check for updates

(C) Author(s) (or their employer(s)) 2019. Re-use permitted under CC BY-NC. No commercial re-use. See rights and permissions. Published by BMJ.

For numbered affiliations see end of article.

Correspondence to Dr Éimhín Mary Ansbro; eimhin.ansbro@Ishtm.ac.uk

\section{ABSTRACT}

Objective We aimed to evaluate an Integrated Diabetic Clinic within a Hospital Outpatient Department (IDCOPD) in a complex humanitarian setting in North Kivu, Democratic Republic of Congo. Specific objectives were to: (1) analyse diabetes intermediate clinical and programmatic outcomes (blood pressure (BP)/glycaemic control, visit volume and frequency); (2) explore the association of key insecurity and related programmatic events with these outcomes; and (3) describe incremental IDC-OPD programme costs.

Design Retrospective cohort analysis of routine programmatic data collected from January 2014 to February 2017; analysis of programme costs for 2014/2015.

Setting Outpatient diabetes programme in Mweso hospital, supported by Médecins sans Frontières, in North Kivu, Demographic Republic of Congo.

Participants Diabetes patients attending IDC-OPD. Outcome measures Intermediate clinical and programmatic outcome trends (BP/ glycaemic control; visit volume/frequency); incremental programme costs.

Results 0 f 243 diabetes patients, $44.6 \%$ were women, median age was 45 (IQR 32-56); $51.4 \%$ were classified type 2. On introduction of IDC-OPD, glucose control improved and patient volume and visit interval increased. During insecurity, control rates were initially maintained by a nurse-provided, scaled-back service, while patient volume and visit interval decreased. Following service suspension due to drug stock-outs, patients were less likely to achieve control, improving on service resumption. Total costs decreased $16 \%$ from 2014 ( $€ 36573$ ) to 2015 (€30 861). Annual cost per patient dropped from $€ 475$ in 2014 to $€ 214$ in 2015 due to reduced supply costs and increased patient numbers.

Conclusions In a chronic conflict setting, we documented that control of diabetes intermediate outcomes was achievable during stable periods. During insecure periods, a simplified, nurse-led model maintained control rates until drug stock-outs occurred. Incremental per patient annual costs were lower than chronic HIV care costs in lowincome settings. Future operational research should define a simplified diabetes care package including emergency preparedness.
Strengths and limitations of this study

- This is the first study of its kind to examine diabetes intermediate clinical outcomes and programme costs in a complex humanitarian setting in subSaharan Africa.

- Using routine clinical and programmatic data collected in a protracted conflict setting, we estimated the effect of insecurity and related programmatic changes on diabetes intermediate clinical outcomes, which, to our knowledge, has not been addressed in the literature to date.

- The study was limited by the relatively small sample size and lack of control group for comparison.

- The costing analysis was descriptive and based on aggregate data and so neither the cost-effectiveness of the programme nor patient-level costs could be determined.

\section{BACKGROUND}

Over the last 40 years, diabetes prevalence has increased sharply worldwide, particularly in low and middle-income countries (LMICs). ${ }^{1}$ However, data on the burden and needs related to diabetes and other noncommunicable diseases (NCDs) are scarce from conflict-affected countries, particularly those in sub-Saharan Africa. ${ }^{12}$ Humanitarian actors have been slow to prioritise diabetes treatment in disaster and post-conflict settings despite reporting increasing presentations of diabetic patients within their programmes. ${ }^{3-6}$ This is due to lack of knowledge on local diabetes epidemiology; limited research on diabetes management or outcomes in crisis settings; a lack of programmatic and policy guidance or tools to support diabetes care in such settings; prioritisation of other health needs; and also a perception that diabetes care is complex and expensive. ${ }^{236-8}$ 
The humanitarian situation in Democratic Republic of Congo (DRC) is considered one of the most complex and challenging worldwide. Prolonged conflict over two decades has resulted in over 5 million deaths, over 4.5 million internally displaced people, the exodus of over 800000 refugees and ongoing political and social instability. ${ }^{910}$ The health system, weakened by prolonged conflict, is challenged by competing health needs in a country ranked 176 of 189 on the human development index despite holding rich natural resources. ${ }^{11}$

On this backdrop, diabetes prevalence is increasing, currently estimated at $4.0 \%-5.4 \% .^{12-14}$ While some factors implicated in the global rise in diabetes prevalence hold true in DRC (demographic change, urbanisation, changing diets and so on) chronic conflict and political instability add additional complexity. Recent reviews and ethnographic evidence point to a link between chronic food insecurity, childhood malnutrition and diabetes. ${ }^{131516}$ In DRC, $43 \%$ of children under 5 years are chronically malnourished and levels of food insecurity have risen sharply, with millions subsisting on World Food Programme rations. ${ }^{17}$ Recent evidence also supports an association between chronic perceived stress and diabetes onset, while patients with diabetes in humanitarian settings focus on suffering and loss as a cause of their illness. ${ }^{16} 18$ Furthermore, in humanitarian crises, people with diabetes are at increased risk of complications and death due to treatment interruption and precarious access to food and water. ${ }^{26}$

Médecins sans Frontières (MSF), a medical humanitarian organisation, has supported healthcare delivery in Mweso, North Kivu, in collaboration with the Ministry of Health since 2008. North Kivu is a rural, impoverished area bordering Rwanda with an estimated population of 365000 . It remains a flash point in the ongoing conflict between shifting rebel groups and government forces, which has been characterised by brutal violence against civilians and destruction of lives and livelihoods. Outbreaks of violence since 2016 have resulted in recurrent waves of population displacement; North Kivu alone hosts 17 internally displaced person camps. MSF supports health services in 4 out of 23 primary healthcare clinics and in Mweso hospital within Masisi District. Mweso hospital serves a catchment area of $\sim 145000$ people, with about 65000 recipients of care living in the immediate vicinity of the hospital.

While a national diabetes programme exists in DRC, available diabetes care is concentrated at hospital level in major cities. ${ }^{19}$ In response to growing patient and provider needs in Mweso, MSF implemented a hospitaloutpatient based diabetes programme in March 2015, the Integrated Diabetic Clinic within a Hospital Outpatient Department (IDC-OPD) in place of the ad hoc care previously undertaken. The IDC-OPD was integrated at the clinical level into usual outpatient activities, with preexisting staff trained to provide this additional service. ${ }^{20}$ The programme comprised a nurse-led, multidisciplinary model, using locally adapted clinical guidelines, patient counselling materials and data collection tools, accompanied by 3 days of specialist training. ${ }^{21}$ The clinic team included: a nurse supervisor, nursing assistant, two doctors, a nutritionist, and education and psychosocial support officers. Diabetes was diagnosed according to WHO guidelines using repeated fasting capillary glucose. Most patients were identified as diabetic and enrolled after acute hospital presentation, while some were identified via the Mweso outpatient department or referring primary care clinics.

Patients received a detailed enrolment assessment, monthly nurse-led follow-up and 6-monthly medical review. The programme included context-adapted dietary advice (accounting for locally available and affordable foods and customs) and psychosocial support, including clinician-moderated peer support groups and involvement of family or friends as treatment supporters. The psychosocial aspects of patients and providers managing diabetes are discussed in a related paper, with major themes from the patient perspective including the difficulty adhering to the recommended diet and barriers to clinic access during outbreaks of violence.$^{22}$ Each patient was given a clinic-held patient file and patient-held passport to facilitate safe passage when armed groups impeded their travel. Clinical guidelines were adapted from MSF, WHO and other international guidance. ${ }^{23}$ Patient educational tools (disease and diet education leaflets) were adapted from Santé Diabète, ${ }^{24}$ a Malian NonGovernmental Organisation, and generic medications, included on MSF's essential drugs list, were prescribed. In the absence of home glucose monitoring, insulin doses were adjusted using single fasting capillary blood glucose (FBG) readings and patients' reported symptoms of hypoglycaemia or hyperglycaemia. Insulin-dependent patients were prescribed human insulin, delivered via needle and syringe, and advised to store this at home in a clay pot, recommended as a safe alternative to refrigeration in similar contexts. ${ }^{25}$

In early 2016, outbreaks of armed violence restricted movement of patients and supplies. Direct attacks on MSF staff and facilities, including an armed robbery and abductions, led to withdrawal of the international staff from Mweso and temporary scaling back of the programme, with local nursing staff dispensing medications to any patients reaching the clinic. Later, the programme was suspended for a period of 6 weeks when supply routes were entirely blocked and drug stocks were exhausted.

A mixed-methods evaluation of the Mweso IDC-OPD programme was undertaken by MSF and included a qualitative evaluation exploring patient and provider clinical and psychosocial challenges, presented elsewhere ${ }^{22}$; and a retrospective review of quantitative programmatic data and cost data collected as part of routine care in a chronic conflict zone, which is reported here. The overall aim of this paper was to evaluate an IDC-OPD in a complex humanitarian setting in North Kivu in DRC. The specific objectives were to: (1) analyse diabetes intermediate clinical and programmatic outcomes (blood pressure 
Table 1 Study periods for evaluation of IDC-OPD programme, Mweso, DRC

\begin{tabular}{lll}
\hline Study period & Description & Dates \\
\hline Training 1 (T1) & Ad hoc diabetes service following basic staff training & 01/01/2014 to 14/03/2015 \\
\hline Training 2 (T2) & IDC-OPD implemented following formal staff training & $15 / 03 / 2015$ to 14/12/2015 \\
\hline Suspend 1 (S1) & $\begin{array}{l}\text { Nurse-provided care without medical supervision; monthly } \\
\text { drug refills provided until buffer stocks were exhausted }\end{array}$ & $15 / 12 / 2015$ to 31/01/2016 \\
Suspend 2 (S2) & No clinical supervision or drugs were provided & $01 / 02 / 2016$ to 14/04/2016 \\
Resume 1 (R1) & $\begin{array}{l}\text { The service was resumed without medical supervision or } \\
\text { quality control }\end{array}$ & $15 / 04 / 2016$ to 31/08/2016 \\
\hline Resume 2 (R2) & Full service resumed until end of data collection period & $01 / 09 / 2016$ to 09/02/2017 \\
\hline
\end{tabular}

DRC, Democratic Republic of Congo; IDC-OPD, Integrated Diabetic Clinic within a Hospital Outpatient Department.

(BP)/glycaemic control, visit frequency and volume); (2) explore the association of key insecurity and related programmatic events with these outcomes; and (3) describe incremental IDC-OPD programme costs.

\section{METHODS}

It has been acknowledged that traditional experimental and evaluation methods may be unfeasible, inappropriate or even unethical to apply in humanitarian settings. ${ }^{26}$ Therefore, we have used a pragmatic approach to utilising programmatic data, with an open cohort design. For the outcome analysis, we conducted a retrospective analysis of routine data of enrolled adults aged $\geq 18$ years from January 2014 to February 2017, examining trends in diabetes outcomes and their association with key programmatic events. The study period was divided into five phases, defined by programmatic changes or periods of heightened insecurity (which impacted service delivery due to staff evacuation, supply chain interruption and reduced patient access). Period T1 refers to ad hoc care delivered before introduction of the IDC-OPD programme (T2). Security incidents in December 2015 prompted a period of service suspension (nurse-only care, with drug pick-ups, glucose testing and minimal treatment adjustments) (S1). Complete suspension followed once drug stocks were exhausted (S2). Limited service resumed in April (R1) until full service recommenced from September 2016 (R2) (table 1).

\section{Data}

Patients were given a unique identification number on enrolment. Data were recorded in paper-based clinicheld files by clinical staff and transferred to an electronic database by a trained data entry operator on a weekly basis. Missing data were discussed with the nurse manager and gaps were filled during follow-up clinical visits. Single data entry was performed on a password-protected Microsoft Excel software application specifically developed by MSF for this programme. Anonymised exports were transferred to the study team on a monthly basis.

Demographic data on patients' age, gender, occupation and village of residence were recorded on enrolment. Cardiovascular risk factors (smoking status, current alcohol use), family history of diabetes, year of diabetes diagnosis and self-reported history of childhood malnutrition and/or tuberculosis were recorded. Clinical parameters: body mass index (BMI), BP measured by manual sphygmomanometer according to local MSF protocols, ${ }^{21}$ FBG; prescribed diabetes drugs (insulin and/or oral hypoglycaemic drugs (OHGs)); and diabetes classification (type I, type II or other) were recorded at each clinical encounter. Medical review at enrolment and 6 monthly thereafter was recorded, including biochemical markers (serum creatinine) and examination for complications (visual acuity, cataract, proteinuria, foot check). Numbers of deaths, transfers out of the area and delays in attendance were also documented. The key intermediate clinical outcome and programme measures used in the analysis are shown in table 2.

\section{Analysis}

Basic demographics were analysed using mean and median and were presented with IQRs. We assessed the relationship of different study periods with the frequency of visits and the impact of study periods on intermediate clinical outcomes, that is, per visit attainment of BP $(<140 / 90 \mathrm{~mm}$ $\mathrm{Hg})$ and glycaemic $(>4.2$ and $\leq 8.3 \mathrm{mmol} / \mathrm{L})$ targets.

To estimate the effect of a period change, we calculated the OR of the odds of having the biomarker under control in a visit in the new period (t) over the odds of having the biomarker controlled in a visit in the previous period $(\mathrm{t}-1)$ : $\mathrm{OR}_{\mathrm{t}}=\mathrm{Odds}_{\mathrm{t}} / \mathrm{Odds}_{\mathrm{t}-1}$. If $\mathrm{OR}_{\mathrm{t}}>1$, this meant that the chances of the biomarker being under control in a visit in period $t$ was greater than the chances of the biomarker being under control in a visit in the previous period $(\mathrm{t}-1)$ (but not necessarily than other periods, $\mathrm{t}-2$, $\mathrm{t}-3$ and so on). Likewise, $\mathrm{OR}_{\mathrm{t}}<1$ implied a reduction in the chances of having the biomarker under control in a visit during period $t$ compared with a visit during the previous period $(\mathrm{t}-1)$. To estimate these $\mathrm{OR}$, we ran a logistic model with period as a categorical variable, suitably coded and adjusted for sex, age (and square and cube terms) and number of visits of the patient (and square term). The models were stratified by whether the patient 
Table 2 Outcome measures used to determine effect of different programme periods on programme delivery and intermediate clinical outcomes

\begin{tabular}{ll}
\hline Category & Variable \\
\hline $\begin{array}{l}\text { Intermediate } \\
\text { clinical }\end{array}$ & $\begin{array}{l}\text { Proportion of visits per month where } \\
\text { outcomes }\end{array}$ \\
& $\begin{array}{l}\text { Proportionts' BP is at target }(<140 / 90 \mathrm{~mm} \mathrm{Hg}) . \\
\text { patients' blood glucose is at target } \\
\text { ( }>4.2 \text { and } \leq 8.3 \mathrm{mmol} / \mathrm{L}) .\end{array}$ \\
$\begin{array}{l}\text { Number and } \\
\text { frequency of } \\
\text { visits }\end{array}$ & $\begin{array}{l}\text { Number of visits per month. } \\
\text { Average visits per patient per month. }\end{array}$ \\
& $\begin{array}{l}\text { Average days from previous visit. } \\
\text { Missing data for BP / glycaemia per visit. }\end{array}$ \\
\hline
\end{tabular}

BP, blood pressure.

was prescribed insulin ( \pm oral hypoglycaemic agents) at the previous visit.

\section{Missing data}

Our main analysis used only complete data; records with missing data were excluded. Few outcome variable data were missing: $<3 \%$ in BP control (most of it in the pretraining period) and $<0.3 \%$ for glycaemic control (online supplement SM1). There were no missing data for date of visit, sex or age.

\section{Costing data and analysis}

For the descriptive, incremental cost analysis, we took a health services perspective. Information related to the nature, location and mode of delivery of the NCD services was collected during a field visit in December 2015 by the study team and was supplemented by informal interviews with clinical and administrative staff. A data analysis tool was designed to collate the relevant financial costs for the study period 2014-2015 from routine programme documents and standard MSF tools including budget, human resources, drug consumption monitoring, logistics/supply tools, clinic records and programme reports. For salary costs, we included the incremental costs of an MSF-employed medical doctor and nurse and an Ministry of Health (MOH)-employed nurse (with salary supplement paid by MSF), dedicating 1 day, two psychosocial workers dedicating 1 hour and a nutritionist dedicating 30 minutes per week to the IDC-OPD service (based on 22 working days per month). Hence, most costs were related to drugs, equipment, disposables and stationary. Key cost items were grouped into: (1) medicine, (2) supplies and (3) staff time. Monthly resource use and unit cost data were recorded and annualised (online supplement SM2); annual total cost, cost per visit and cost per patient were reported in Euro (€) for 2014 before formal implementation of the IDC-OPD programme and for 2015 during full implementation.

\section{Patient and public involvement}

Patients were not involved in the design or conduct of this study.

\section{RESULTS}

Between 1 January 2014 and 9 February 2017, 243 patients were enrolled in the IDC-OPD programme (online supplement SM3). Median age was 45 years (IQR $32-56) ; 44.4 \%$ of the cohort was female. For adults $\geq 18$ years $(\mathrm{n}=219)$, mean BMI was $21.3 \mathrm{~kg} / \mathrm{m}^{2}$ and $31.1 \%$ were underweight (BMI $<18.5 \mathrm{~kg} / \mathrm{m}^{2}$ ). On enrolment, $8.2 \%$ were current smokers; $24.8 \%$ reported recent alcohol intake; self-reported medical history included: 9.1\% hypertension, $2.2 \%$ cardiovascular disease, $2.7 \%$ tuberculosis and $8.7 \%$ malnutrition. Half were classified clinically as type II diabetic $(51 \% ; n=125) ; 26 \%(n=62)$ as type $\mathrm{I}$; and $23 \%(\mathrm{n}=56)$ were either unclassified or classed as 'other' (online supplement SM3).

\section{Trends in outcomes and impact of programmatic events}

Numbers of visits and appointment intervals increased after the introduction of the systematic approach to diabetes care, which included monthly review appointments for stable patients (T2) (figure 1; online supplement SM4). During the period of scaled back service (S1), visit numbers initially climbed while the visit interval decreased, which may reflect increased visit frequency due to short-term drug supplies. Once drug buffer stock was exhausted, visit numbers dropped off sharply. Patients may have avoided or were prevented from attending due to security conditions.

BP control was consistently better than glycaemic control (of note, patients without diagnosed hypertension were included in the analysis) (figure 2). By period T2, $\sim 80 \%$ of visits achieved $\mathrm{BP}$ and $60 \%$ achieved glycaemic control. There was a notable drop in control of both parameters during programme suspension with a gradual improvement on resumption. BP control was consistently better, while glycaemic control was consistently worse, in patients prescribed insulin $( \pm \mathrm{OHGs})$ compared with those prescribed OHGs alone (online supplement SM5), which may be because the former group contained relatively young type I and malnutrition-related diabetics.

The results of the OR calculations were unexpected. Odds of attaining BP control appeared to worsen following implementation of the formal IDC-OPD programme (T2 vs T1), while odds of attaining glucose control improved, perhaps because care was initially focused on glucose control (online supplement SM6). On scaling back the service (S1), control of both parameters seemed to improve, possibly because the service itself or the subset of patients reaching it during the insecure period were somehow different. Once medications supplies were exhausted (S2), control of both parameters seemed to worsen, but control was regained on service resumption. Stratifying by insulin prescription showed similar results (online supplement SM5). 


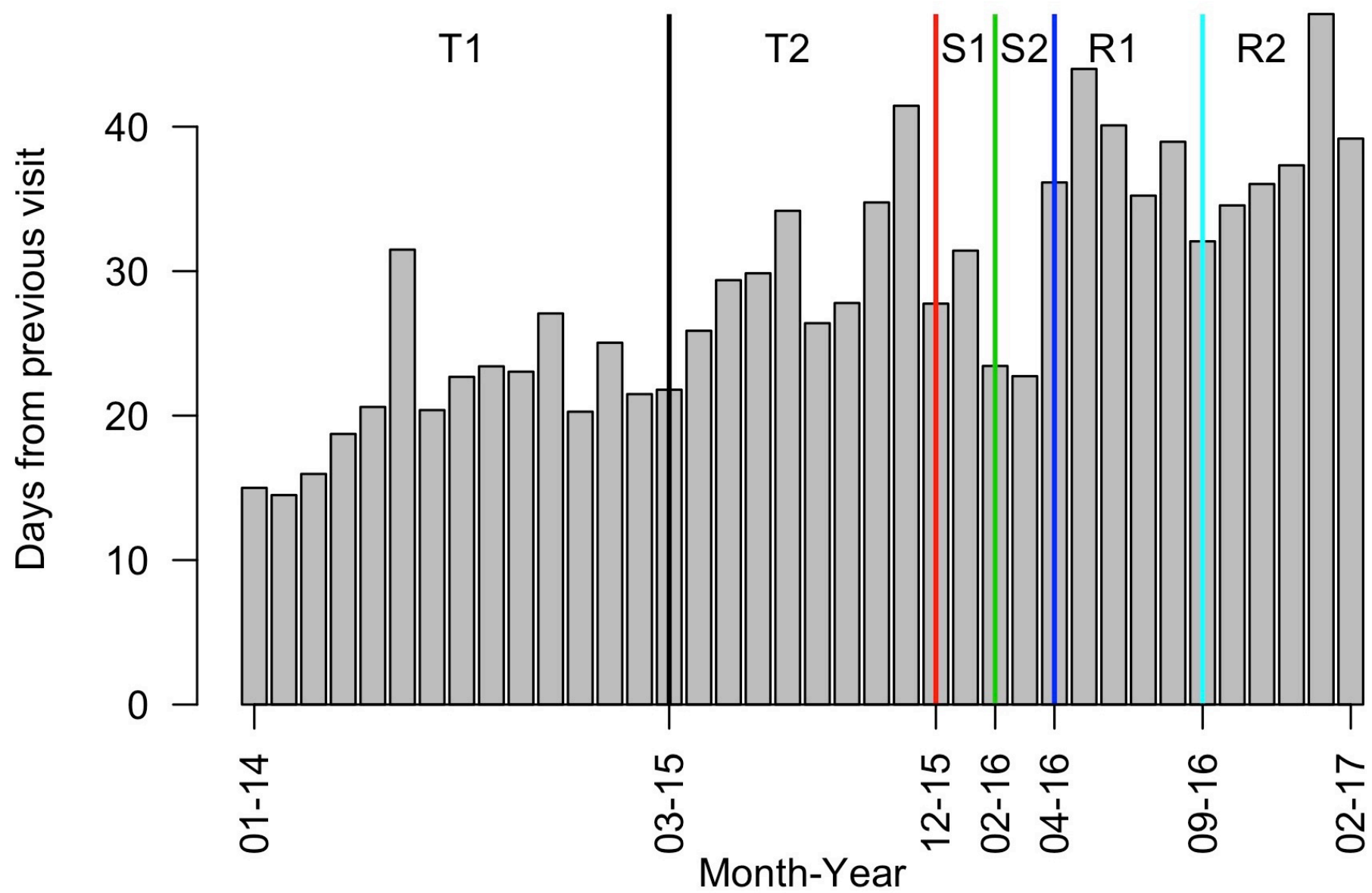

Figure 1 Average number of days from previous visit per month for Mweso IDC-OPD service. IDC-OPD, Integrated Diabetic Clinic within a Hospital Outpatient Department.

\section{Costs of providing diabetes care}

The total costs of diabetes care in 2014 and 2015 were $\sim € 37000$ and $€ 31000$, respectively (table 3 ). Supplies were the major driver of costs each year. The greatest costs in 2014 were for latex gloves, glucometers and glucometer strips; in 2015, they were for glucometers, strips and lancets (online supplement SM2). While medication costs increased in 2015 relative to 2014, staff costs remained unchanged and total costs decreased, largely driven by reduced excess consumption of latex gloves after it was identified as an issue during the IDP-OPD training sessions. The total number of patients and number of visits increased significantly from 2014 to 2015, rising from 77 and 626 to 144 and 1103, respectively. Thus, cost per-patient per-year (PPPY) dropped from $€ 475$ to $€ 214$ and cost per-visit was halved from $€ 58$ to $€ 28$. This was due to the combined effect of higher patient numbers, greater total number of visits and lower supply costs in 2015 compared with 2014 (online supplement SM2).

\section{DISCUSSION}

This evaluation of a chronic disease programme in a complex conflict setting, using routine programmatic and cost data, provided lessons, which may improve clinical care and programme design. To the best of our knowledge, the influence of treatment interruption and insecurity on diabetes management in humanitarian settings has not been addressed in the literature. Similarly, we are not aware of costing studies of diabetes care in crisis settings.

Our results show that glycaemic control was similar or better to that documented in other humanitarian or lowincome settings (using different targets) and, while it was positively impacted by programmatic changes, control clearly deteriorated during periods of heightened insecurity. ${ }^{27}$ Our findings also indicate that, in a population previously undergoing regular supervision, a simplified nurse-provided, algorithm-driven service with consistent medication supply may be as effective as close medical supervision in maintaining disease control, particularly during periods of service interruption. Medical input could thus be focused on achieving glycaemic control in patients prescribed insulin, who appeared most affected by service interruption. We also note the lack of evidence supporting management of what we believed to be malnutrition-related diabetes.

Intermittent outbreaks of armed conflict limited patient access and disrupted supply chains, impeding continuity of care. We suggest that in high-insecurity settings, chronic disease programmes should focus on 


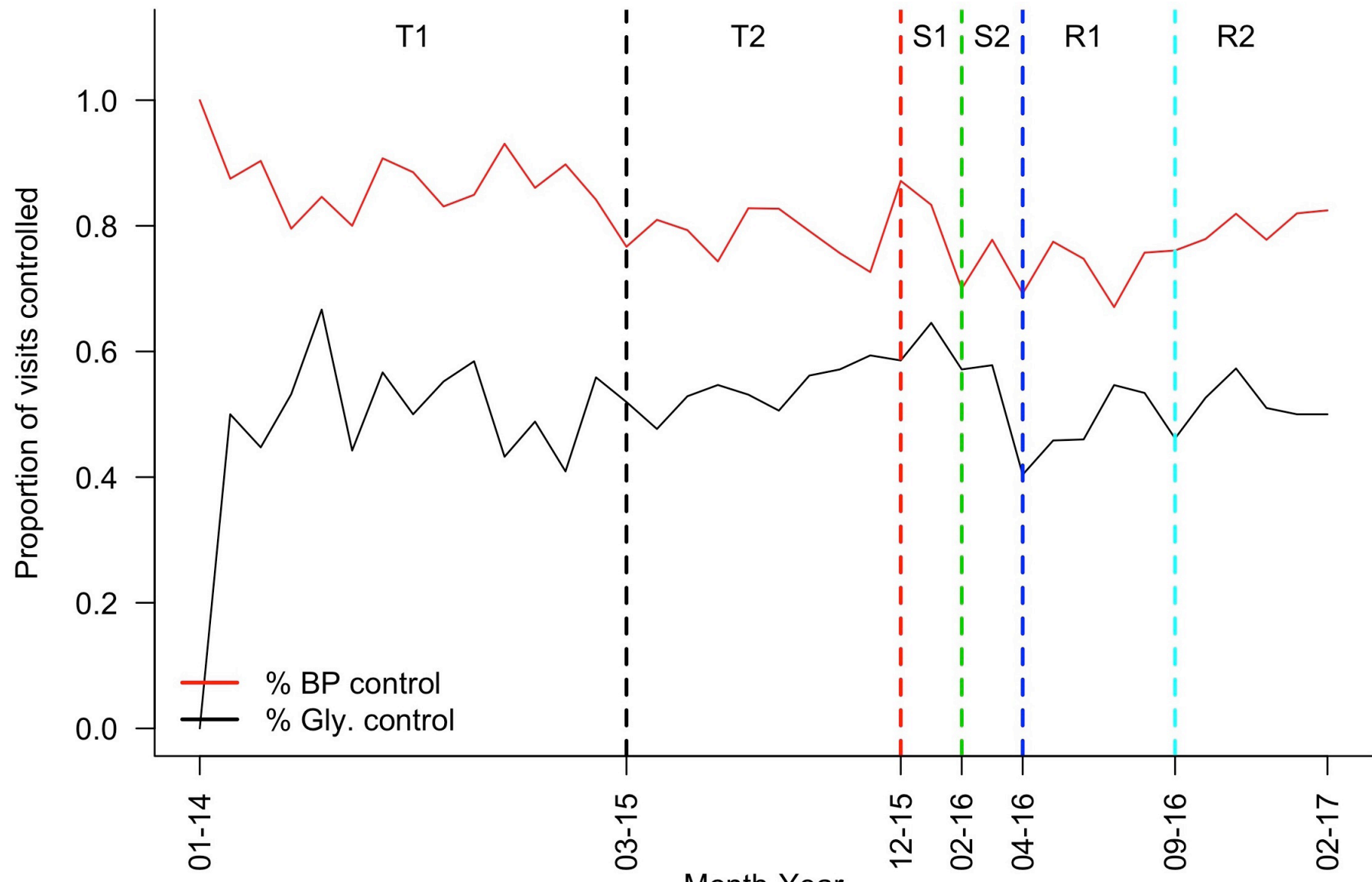

Figure 2 Proportion of visits with BP or glycaemia at target by month, Mweso IDC-OPD service. BP, blood pressure; IDC-OPD, Integrated Diabetic Clinic within a Hospital Outpatient Department.

preparing patients, staff and supply chains to pre-empt treatment interruption during insecure periods, learning from HIV programme experiences in similar settings. ${ }^{28}$ Preparation could include: triaging patients by vulnerability (eg, prioritising insulin-dependent diabetic patients, those with established complications and/or living far from the facility); enhancing patients' health literacy and self-management education and provision of patient-held personal treatment plans and emergency kits (including several months' supply of medications, such as

Table 3 Costs $(€)$ of diabetes care in 2014 and 2015, Mweso IDC-OPD service

\begin{tabular}{llcrc}
\hline Cost category & $\mathbf{2 0 1 4}$ & $\begin{array}{l}\text { \% 2014 } \\
\text { costs }\end{array}$ & $\mathbf{2 0 1 5}$ & $\begin{array}{l}\text { \% 2015 } \\
\text { costs }\end{array}$ \\
\hline Medicine costs & 5202 & 14 & 7746 & 25 \\
Supply costs & 25435 & 70 & 17180 & 56 \\
Staff costs & 5935 & 16 & 5935 & 19 \\
Total costs & 36573 & 100 & 30861 & 100 \\
Costs per visit & 58 & & 28 & \\
Costs per patient & 475 & & 214 &
\end{tabular}

IDC-OPD, Integrated Diabetic Clinic within a Hospital Outpatient Department. insulin, delivery devices and guidance, as appropriate) to facilitate self-care during insecure periods; building staff capacity to allow for flexibility of roles in crises; establishing networks with other chronic disease programmes; and stockpiling and secure storage of medications. ${ }^{5} 2829$ Technology could facilitate continued patient treatment support when access to facilities is impossible, for example, via mobile phone short message service (SMS) messaging or decentralisation of care to community-based health workers furnished with clinical decision support tools or supported via telemedicine.

The relatively poorer glycaemic control in insulinprescribed patients may reflect either disease severity or the challenges associated with insulin therapy. Adherence to daily insulin injections is difficult anywhere; in Mweso, the security, financial and geographical barriers to accessing insulin and the unavailability, unaffordability and burden for families of the recommended diabetes diet, may additionally contribute to poor adherence. ${ }^{22}$ In this programme, clinicians adjusted insulin doses based on a single fasting glucose reading taken in clinic and on patients' reported symptoms in the absence of home glucose monitoring and, therefore, dose adjustment was cautious and treatment targets were conservative.

There is limited, although growing, evidence on the incidence, prevalence and characterisation of diabetes 
in sub-Saharan Africa, which our findings broadly reflect. $^{30}$ Several reviews and recent ethnographic evidence describe 'atypical' forms of diabetes, which may complicate diagnosis, classification and management. These include 'ketosis-prone atypical diabetes mellitus' and 'malnutrition-related diabetes. ${ }^{131631}$ Local prevalence studies support the existence of the latter in the DRC, which is in keeping with the high proportion of underweight adults and 'unclassified' diabetics in our cohort. ${ }^{14}{ }^{32}$ It is unclear whether malnutrition is causative, associated with hyperglycaemia or with pancreatic insufficiency and further study of diabetes epidemiology in DRC is needed, exploring factors such as childhood malnutrition, food insecurity and underweight and use of calorie-dense therapeutic foods. ${ }^{31}$ Moreover, little evidence exists to guide either malnutrition-related diabetes care or the effective management of insulin in humanitarian settings, particularly in the absence of home or community-based glucose testing. $^{37}$

The total cost of care delivery decreased by $16 \%$ from 2014 to 2015 despite increased visit and patient numbers. This was largely due to decreased supply costs, driven by the 100-fold reduction in consumption of latex gloves following IDC-OPD training. Efficiencies of supply consumption and patient throughput (more visits and more patients seen by the same number of staff) contributed to reducing PPPY costs by 55\% from $€ 475$ in 2014 to $€ 214$ in 2015 .

To our knowledge, there is no available literature to compare cost per patient or per visit for diabetes care (or NCD care generally) delivered in unstable humanitarian settings. A study from Ghana reported a per patient annual direct cost of US\$372.65 for hospital-delivered diabetes care in 2005. For a potential comparator, we looked at the cost of delivering chronic care for HIV, the main life-long condition with which humanitarian actors have traditionally engaged. The 2015 PPPY cost reported in this study is far lower than that reported by PEPFAR and others to deliver chronic HIV care programmes in LMICs in SSA. ${ }^{33} 34$ In terms of cost structure, supplies were the major cost driver in the Ghanaian study (syringes, lancets and strips), whereas other analyses of diabetes care in SSA identified medications, and specifically insulin, as the main cost contributor. ${ }^{35} 36$

\section{Strengths and limitations}

Using routine clinical and programmatic data, with minimal service disruption, we have explored clinical outcomes of a chronic disease programme in a protracted conflict setting and the influence of periods of heightened insecurity on intermediate clinical outcomes and on service delivery. Each patient who attended in a given month contributed data, irrespective of whether they ever experienced a treatment interruption. Our study provides new costing information for humanitarian actors to support the initiation or adaptation of specific NCD programmes and may potentially support scale up of similar services in DRC (and other conflict-affected settings). We concluded that the incremental cost of adding an outpatient diabetes service to a humanitarian health programme in a rural hospital setting may be achieved at a cost similar to that of delivering chronic HIV programmes. While we cannot confirm whether an external audit of cost data had taken place, we are confident in the quality of these data due to MSF's robust systems and oversight by strong in-country and international teams.

Given the logistical and ethical challenges of undertaking research in conflict settings, we acknowledge that there are a number of study limitations. We had a relatively small sample size and no control group for comparison. We did not explore per patient control of clinical parameters over time, control by diabetes type (or age), appropriateness of prescribing, patient-reported outcomes or the influence of psychosocial factors, diet or adherence in each study phase since these data were unavailable. Gestational diabetes was not addressed since this was managed within antenatal services. Our costing analysis was descriptive so we could not comment on programme cost-effectiveness. Costing data were presented as average annual costs and did not explore the impact of various programme periods on costs. Since our cost data were aggregate, we could not explore patient-level costs or account for patient heterogeneity. While our findings may not be generalisable to other complex humanitarian settings or to other providers' diabetes programmes in the DRC, our study contributes knowledge on key challenges and suggests solutions, which may be more broadly applicable.

Future research is needed in complex humanitarian settings to evaluate simplified, task-shared models of diabetes care, including culturally and contextually relevant psychosocial support and dietary advice; to optimise insulin management; and to evaluate emergency preparedness plans and technology-facilitated remote patient support. ${ }^{3} 581329$ We recommend that future prospective studies should explore per-patient outcomes (while also examining programme-level outcomes as done in this study). We suggest including a control group; collecting additional outcome variables, such as complication rates and patient-reported outcomes, for example, quality-of-life, functionality and mental health outcomes; and exploring the impact of psychosocial stressors and treatment interruption on clinical outcomes. We also suggest that cost-effectiveness studies of different models of diabetes care, including use of technology-facilitated remote support, and patient level costing studies from both provider and patient perspectives should be undertaken, exploring patient heterogeneity and direct and indirect patient costs.

\section{CONCLUSION}

Our results help develop the sparse knowledge on the prevalence and characterisation of diabetes in subSaharan Africa. They demonstrate that diabetes care is 
feasible even in complex humanitarian emergencies, and at a cost that is lower than chronic HIV care. The results also indicate that the Mweso IDC-OPD programme could be further simplified to involve drug collection along with nurse-led, algorithm-guided treatment adjustment. We suggest that chronic disease programmes in unstable settings should engage in emergency preparedness, learning from the experience of HIV programmes in similar settings. Future research is needed to evaluate simplified, task-shared models of diabetes care and management; and to evaluate emergency preparedness plans and technology-facilitated remote patient support.

\section{Author affiliations}

${ }^{1}$ Manson Unit, Médecins sans Frontières, London, UK

${ }^{2}$ Centre for Global Chronic Conditions, Faculty of Public Health and Policy, London

School of Hygiene and Tropical Medicine, London, UK

${ }^{3}$ Mweso Hospital, Médecins Sans Frontières Operational Centre Amsterdam,

Mweso, Congo (the Democratic Republic of the)

${ }^{4}$ Department of Non-communicable Disease Epidemiology, Faculty of Epidemiology and Population Health, London School of Hygiene and Tropical Medicine, London, UK ${ }^{5}$ Department of Health Services Research and Policy, Faculty of Public Health and Policy, London School of Hygiene and Tropical Medicine, London, UK ${ }^{6}$ Centre for Global Chronic Conditions, Faculty of Epidemiology and Population Health, London School of Hygiene and Tropical Medicine, London, UK ${ }^{7}$ Centre for Global Chronic Conditions, Faculty of Public Health and Policy, London School of Hygiene and Tropical Medicine, London, UK

\section{Twitter Éimhín Mary Ansbro @EimhinA}

Acknowledgements We gratefully acknowledge the staff and patients of the MSF IDC-OPD programme for their contribution to this study. We thank Sarah Venis for her helpful review of the article. This work was presented at MSF Scientific Days Conference in London, May 2018.

Contributors KJ and BR were involved in study conception. EMA, GC, KJ, DP-M, PP and BR contributed to study design and interpretation of data. DP-M and ZS analysed the data. MB contributed to data collection. EMA drafted the manuscript. All authors reviewed drafts and approved the final version.

Funding This study was funded by Médecins sans Frontières.

Competing interests None declared.

Patient consent for publication Not required.

Ethics approval This study was approved by the Ministry of Health of North Kivu Province, DRC, and by the Médecins sans Frontières Ethics Review Board (ID 1542). Information sheets on the clinic walls provided details of the evaluation; no specific consent was sought from patients for use of their routine clinical data.

Provenance and peer review Not commissioned; externally peer reviewed.

Data availability statement The datasets are available from MSF on request by researchers who fulfil certain criteria and under the auspices of a data sharing agreement.

Open access This is an open access article distributed in accordance with the Creative Commons Attribution Non Commercial (CC BY-NC 4.0) license, which permits others to distribute, remix, adapt, build upon this work non-commercially, and license their derivative works on different terms, provided the original work is properly cited, appropriate credit is given, any changes made indicated, and the use is non-commercial. See: http://creativecommons.org/licenses/by-nc/4.0/.

ORCID iD

Éimhín Mary Ansbro http://orcid.org/0000-0002-2291-1652

\section{REFERENCES}

1 NCD Risk Factor Collaboration (NCD-RisC). Worldwide trends in diabetes since 1980: a pooled analysis of 751 population-based studies with 4.4 million participants. Lancet 2016;387:1513-30.
2 Kehlenbrink S, Smith J, Ansbro Éimhín, et al. The burden of diabetes and use of diabetes care in humanitarian crises in lowincome and middle-income countries. Lancet Diabetes Endocrinol 2019;7:638-47.

3 Demaio A, Jamieson J, Horn R, et al. Non-Communicable diseases in emergencies: a call to action. PLoS Curr 2013;5. doi:10.1371/ currents.dis.53e08b951d59ff913ab8b9bb51c4d0de. [Epub ahead of print: 06 Sep 2013].

4 Roberts B, Patel P, McKee M. Noncommunicable diseases and postconflict countries. Bull World Health Organ 2011;90:2-2A.

5 Besançon S, Fall I-S, Doré M, et al. Diabetes in an emergency context: the Malian case study. Confl Health 2015:9:15.

6 Boulle P, Kehlenbrink S, Smith J, et al. Challenges associated with providing diabetes care in humanitarian settings. Lancet Diabetes Endocrinol 2019;7:648-56.

7 Ruby A, Knight A, Perel P, et al. The effectiveness of interventions for non-communicable diseases in humanitarian crises: a systematic review. PLoS One 2015;10:e0138303.

8 Jobanputra K, Boulle P, Roberts B, et al. Three steps to improve management of noncommunicable diseases in humanitarian crises. PLoS Med 2016;13:e1002180.

9 International Rescue Committee. Mortality in the Democratic Republic of Congo: an ongoing crisis | international rescue Committee (IRC), 2007. Available: https://www.rescue.org/report/ mortality-democratic-republic-congo-ongoing-crisis [Accessed 10 Dec 2017].

10 UNHCR. UNHCR global trends 2018. Geneva, 2019. Available: https://www.unhcr.org/uk/statistics/unhcrstats/5d08d7ee7/unhcrglobal-trends-2018.html [Accessed 1 Jul 2019].

11 Human Development Indices and Indicators. Statistical update Congo (Democratic Republic of the), 2018. Available: http://hdr.undp. org/en/data [Accessed 30 Jul 2019].

12 Whiting DR, Guariguata L, Weil C, et al. IDF diabetes atlas: global estimates of the prevalence of diabetes for 2011 and 2030. Diabetes Res Clin Pract 2011;94:311-21.

13 Atun R, Davies JI, Gale EAM, et al. Diabetes in sub-Saharan Africa: from clinical care to health policy. Lancet Diabetes Endocrinol 2017;5:622-67.

14 Muyer MT, Muls E, Mapatano MA, et al. Diabetes and intermediate hyperglycaemia in Kisantu, DR Congo: a cross-sectional prevalence study. BMJ Open 2012;2:e001911.

15 A sub-Saharan African perspective of diabetes. Available: file:///C:/ Users/DAnsbro/Downloads/0f317533c181fe640b000000.pdf [Accessed 30 Jan 2015].

16 Carruth L, Mendenhall E. "Wasting away": Diabetes, food insecurity, and medical insecurity in the Somali Region of Ethiopia. Soc Sci Med 2019;228:155-63.

17 Food and Agriculture Organisation of the United Nations. FAO News Article: Food insecurity soars in conflict-ridden Democratic Republic of Congo. Available: http://www.fao.org/news/story/en/ item/1028934/icode/ [Accessed 5 Aug 2019].

18 Harris ML, Oldmeadow C, Hure A, et al. Stress increases the risk of type 2 diabetes onset in women: a 12-year longitudinal study using causal modelling. PLoS One 2017;12:e0172126.

19 World diabetes Foundation. Projects. improving diabetes care WDF05-128. Available: https://www.worlddiabetesfoundation.org/ projects/congo-kinshasa-wdf05-128 [Accessed 5 Aug 2019].

20 Valentijn PP, Schepman SM, Opheij W, et al. Understanding integrated care: a comprehensive conceptual framework based on the integrative functions of primary care. Int $J$ Integr Care 2013;13:e010.

21 ÉM A. Msf OCA Mweswo guide de diabète pour patients ambulatoires 2015

22 Murphy A, Biringanine M, Roberts B, et al. Diabetes care in a complex humanitarian emergency setting: a qualitative evaluation. BMC Health Serv Res 2017;17:431.

23 Jobanputra K, Ansbro E. Diabetes service evaluation (2014-2017) main findings from Mweso, North Kivu, the Democratic Republic of Congo, 2018. Available: https://fieldresearch.msf.org/handle/10144/ 619307 [Accessed 12 May 2019].

24 ONG Santé Diabète / NGO Health Diabetes - Home. Available: https://santediabete.org/en/ [Accessed 20 Aug 2018].

25 Ogle GD, Abdullah M, Mason D, et al. Insulin storage in hot climates without refrigeration: temperature reduction efficacy of clay POTS and other techniques. Diabet Med 2016;33:1544-53.

26 Blanchet K, Ramesh A, Frison S, et al. Evidence on public health interventions in humanitarian crises. Lancet 2017;390:2287-96.

27 Cohen DB, Allain TJ, Glover S, et al. A survey of the management, control, and complications of diabetes mellitus in patients attending a diabetes clinic in Blantyre, Malawi, an area of high HIV prevalence. Am J Trop Med Hyg 2010;83:575-81. 
28 Culbert H, Tu D, O'Brien DP, et al. Hiv treatment in a conflict setting: outcomes and experiences from Bukavu, Democratic Republic of the Congo. PLoS Med 2007;4:e129.

29 Slama S, Kim H-J, Roglic G, et al. Care of non-communicable diseases in emergencies. Lancet 2017;389:326-30.

30 Hall V, Thomsen RW, Henriksen O, et al. Diabetes in sub Saharan Africa 1999-2011: epidemiology and public health implications. A systematic review. BMC Public Health 2011;11:564.

31 Gill GV, Mbanya J-C, Ramaiya KL, et al. A sub-Saharan African perspective of diabetes. Diabetologia 2009;52:8-16.

32 Hightower JD, Hightower CM, Vázquez BYS, et al. Incident prediabetes/diabetes and blood pressure in urban and rural communities in the Democratic Republic of Congo. Vasc Health Risk Manag 2011;7:483-9.
33 Bikilla AD, Jerene D, Robberstad B, et al. Cost estimates of HIV care and treatment with and without anti-retroviral therapy at Arba Minch hospital in southern Ethiopia. Cost Eff Resour Alloc 2009;7.

34 Report on Costs of Treatment in the President's Emergency Plan for AIDS Relief (PEPFAR) Background, 2013. Available: https://www. pepfar.gov/documents/organization/212059.pdf [Accessed 21 Dec 2017].

35 Quaye EA, Amporful EO, Akweongo P, et al. Analysis of the financial cost of diabetes mellitus in four cocoa clinics of Ghana. Value Health Reg Issues 2015;7:49-53.

36 Kirigia JM, Sambo HB, Sambo LG, et al. Economic burden of diabetes mellitus in the who African region. BMC Int Health Hum Rights 2009;9:6. 